\title{
The Early
}

Development of Neutron Diffraction: Science in the Wings of the Manhattan Project

Presented to the

Bragg Symposium: Celebrating 100 years of X-Ray Crystallography

Thomas E. Mason Director

Adelaide, SA, Australia December 6, 2012

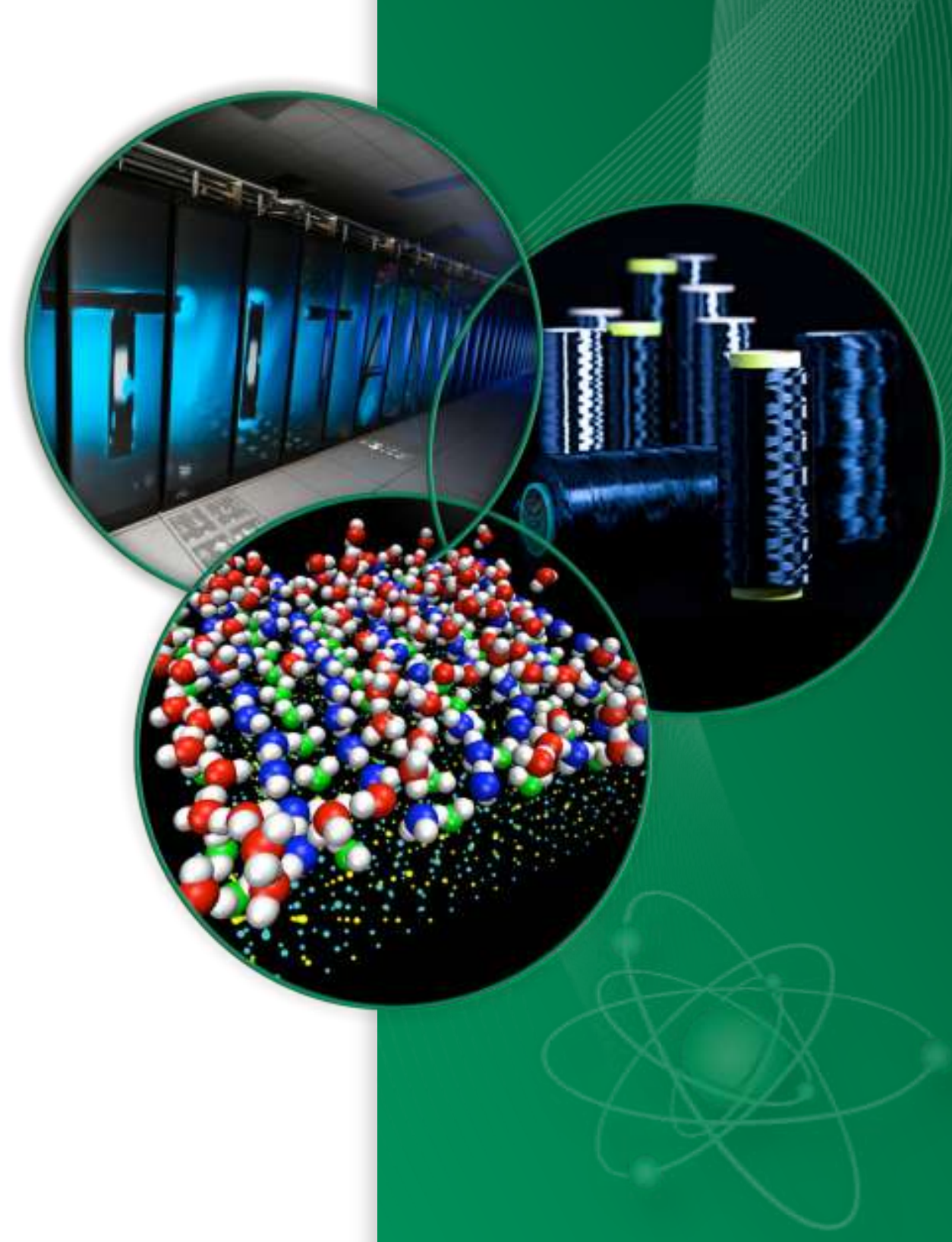




\section{Neutron scattering: The pre-reactor period}
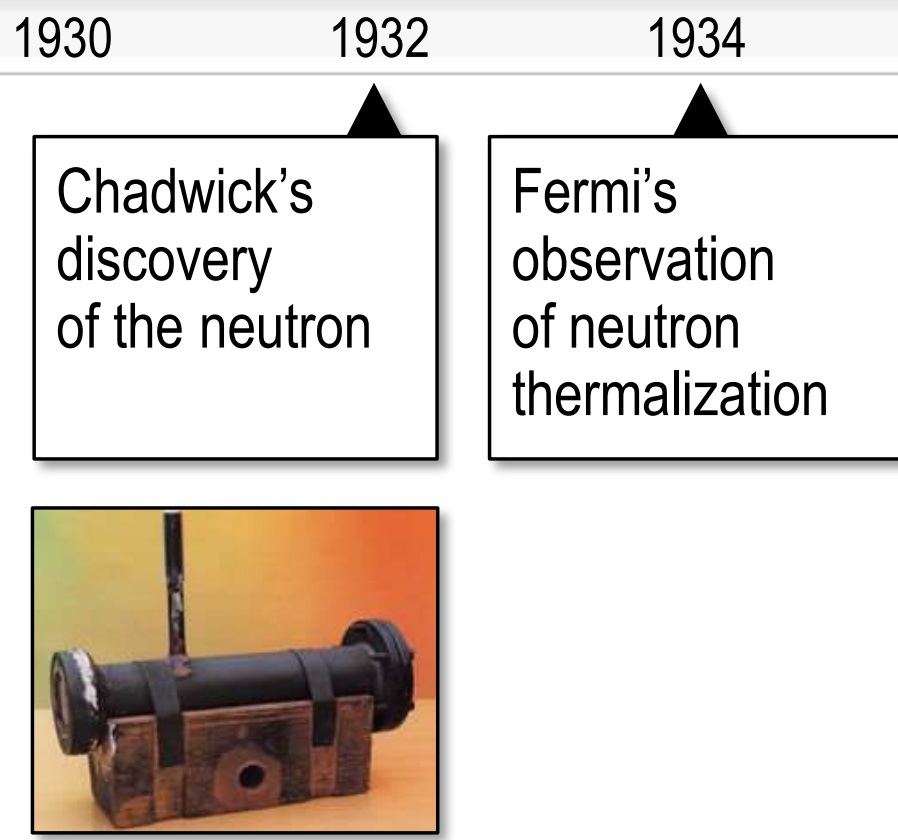

\begin{tabular}{|l|}
\hline Demonstrations \\
of coherent \\
neutron \\
diffraction \\
(Bragg \\
scattering \\
by crystal \\
lattice planes) \\
- Mitchell \\
and Powers \\
- von Halban \\
and Preiswerk \\
\hline
\end{tabular}

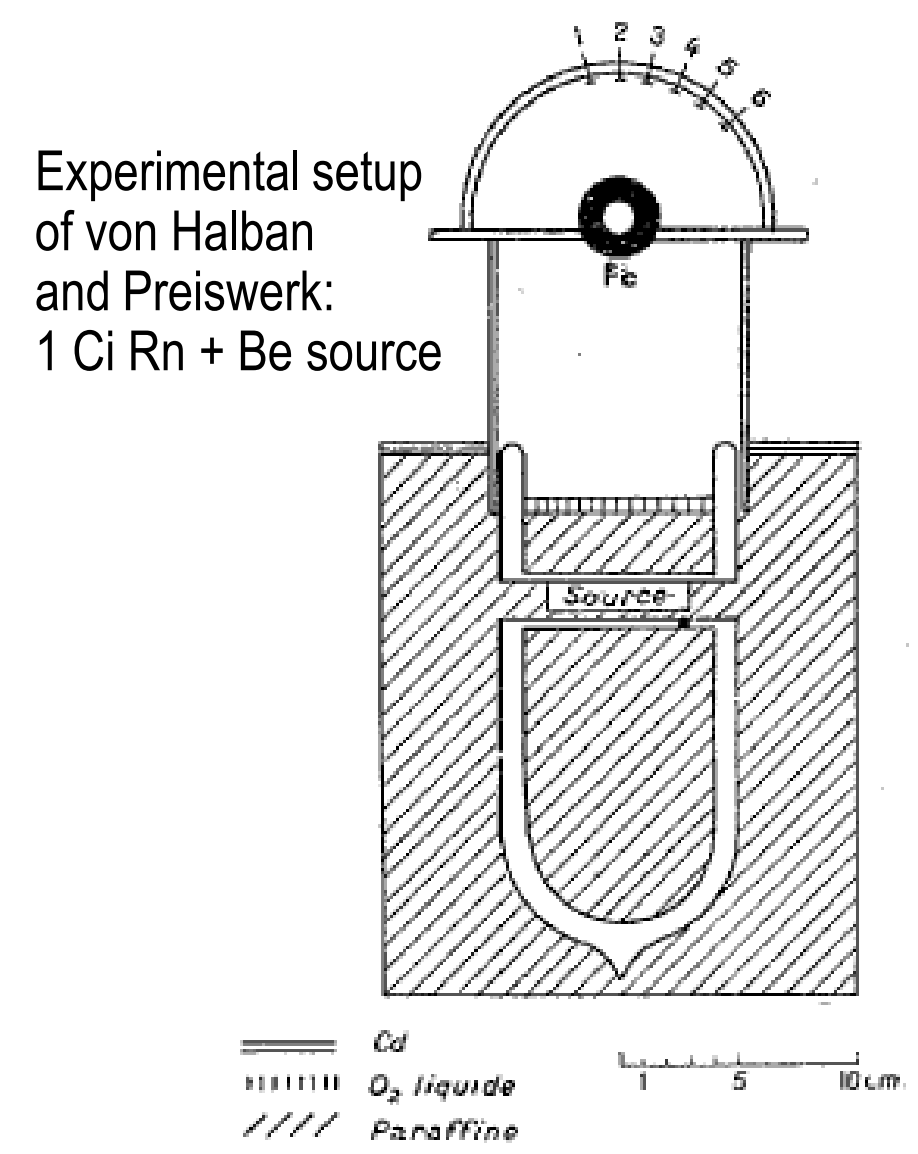




\title{
Successful operation of CP-1 marked the start of a new era
}

\author{
$\begin{array}{lllll}1942 & 1944 & 1946 & 1948 & 1950\end{array}$ \\ DEC. 21942 START-UP \\ FIRST SELF-SUSTAINING CHAIN REACTION \\ NEUTRON INTENSITY IN THE PILE AS RECORDED BY A GALVANOMETER
}

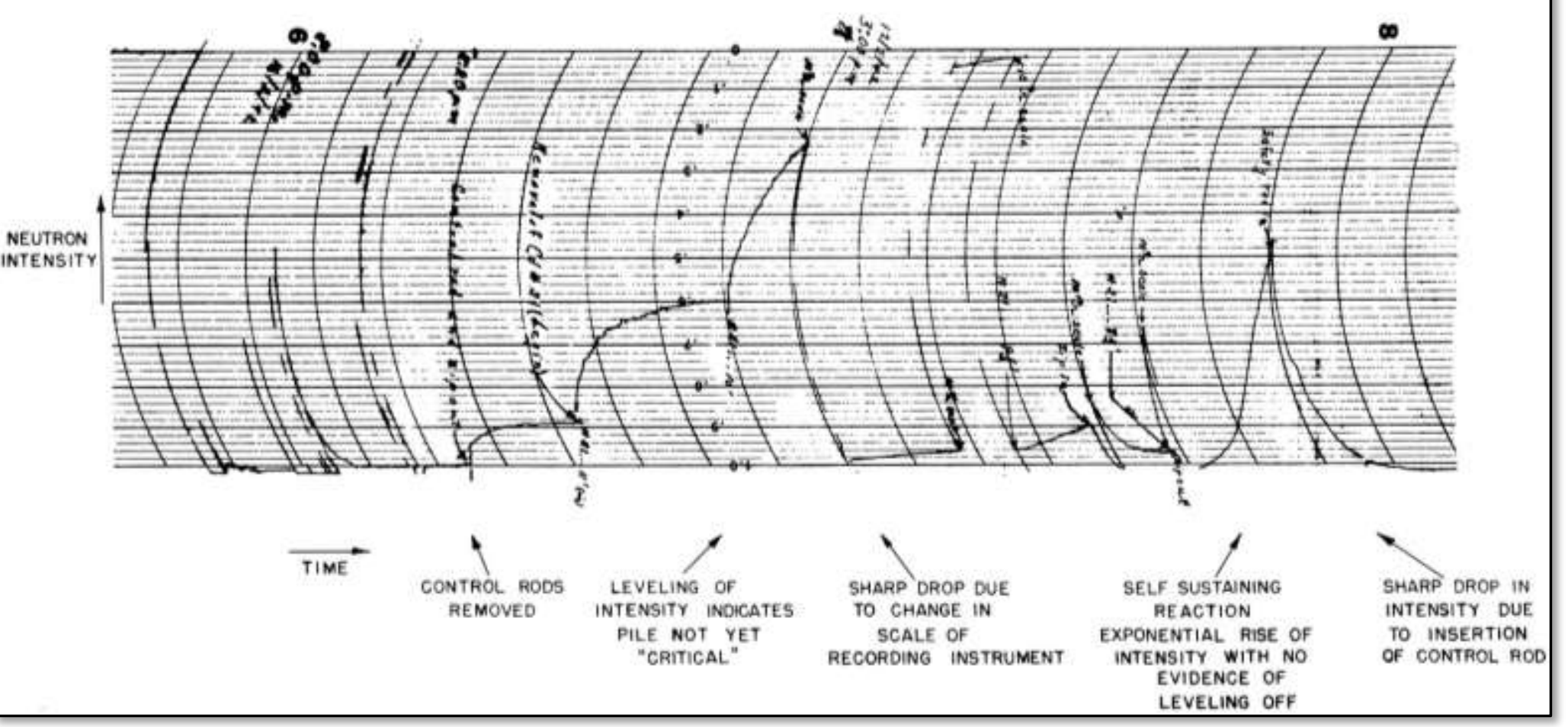
OAT RIDGE NATIONAL LABORATORY 


\section{Early nuclear reactors: The X-10 Pile (Graphite Reactor)}

\begin{tabular}{l|l}
19401942 & $1944 \quad 1946 \quad 1948$ \\
\hline $\begin{array}{l}\text { First criticality: } \\
\text { 4 November 1943 }\end{array}$ \\
\hline \multicolumn{2}{|l}{$\begin{array}{l}\text { Location } \\
\text { Clinton Laboratories } \\
\text { (later Oak Ridge } \\
\text { National Laboratory) } \\
\text { Tennessee }\end{array}$} \\
\hline Fuel & Natural uranium \\
\hline Power & $1,000 \mathrm{~kW}$ \\
\hline Moderator & Graphite \\
\hline Coolant & Air \\
\hline Flux & $1 \times 10^{12} \mathrm{~cm}^{-2} \mathrm{~s}^{-1}$ \\
\hline
\end{tabular}

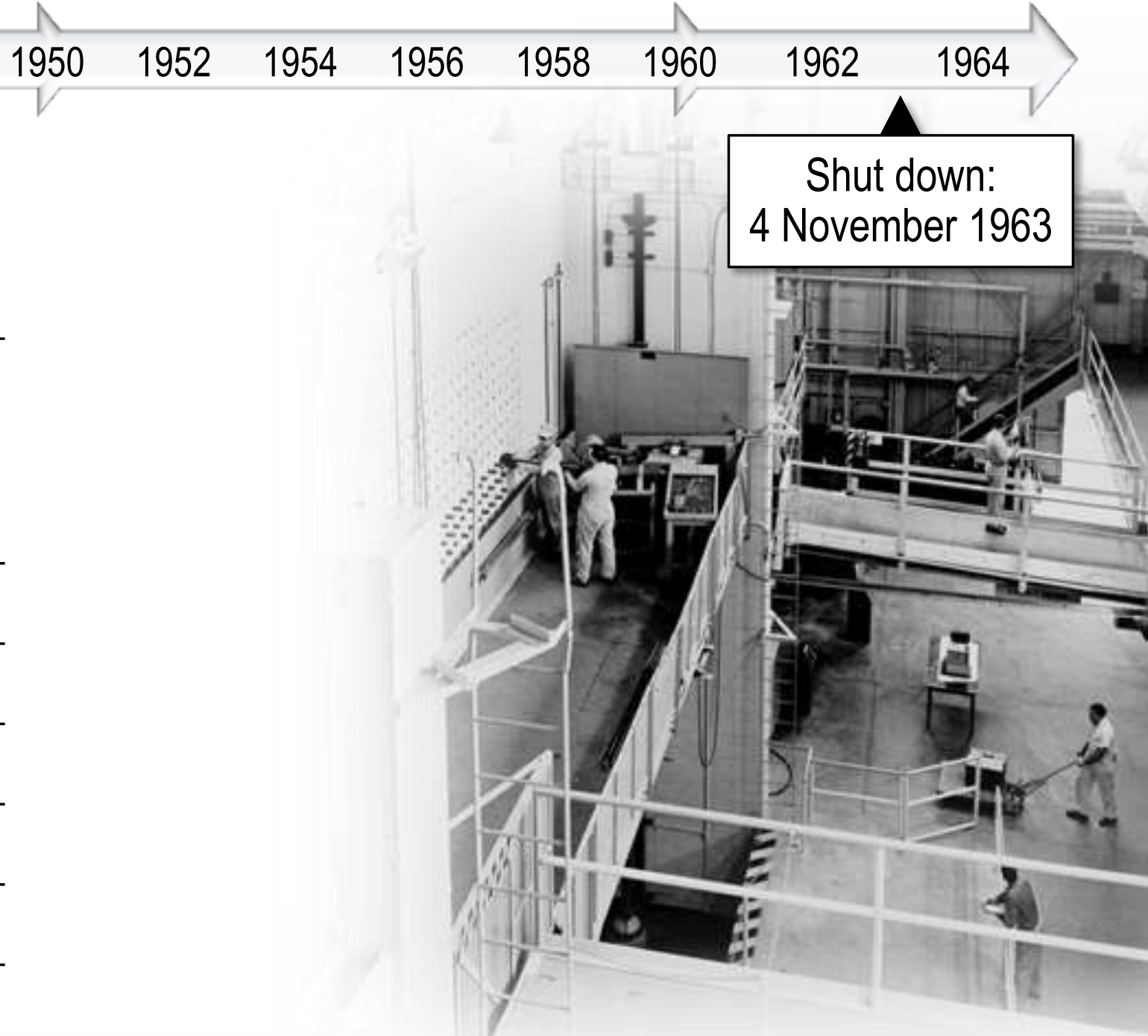




\section{Early nuclear reactors: CP-3 (Chicago Pile 3)}

\begin{tabular}{l|l}
1940 & \multicolumn{1}{|c}{1942} \\
\cline { 2 - 2 } & $\begin{array}{l}\text { First criticality: } \\
15 \text { May 1944 }\end{array}$ \\
\hline Location & $\begin{array}{l}\text { Chicago Metallurgical } \\
\text { Laboratory, Site A } \\
\text { (later Argonne } \\
\text { National Laboratory), Illinois }\end{array}$ \\
\hline Fuel & Natural uranium \\
\hline Power & $300 \mathrm{~kW}$ \\
\hline Moderator & Heavy water \\
\hline Coolant & Circulated moderator \\
\hline Flux & $1 \times 10^{12} \mathrm{~cm}^{-2} \mathrm{~s}^{-1}$ \\
\hline
\end{tabular}
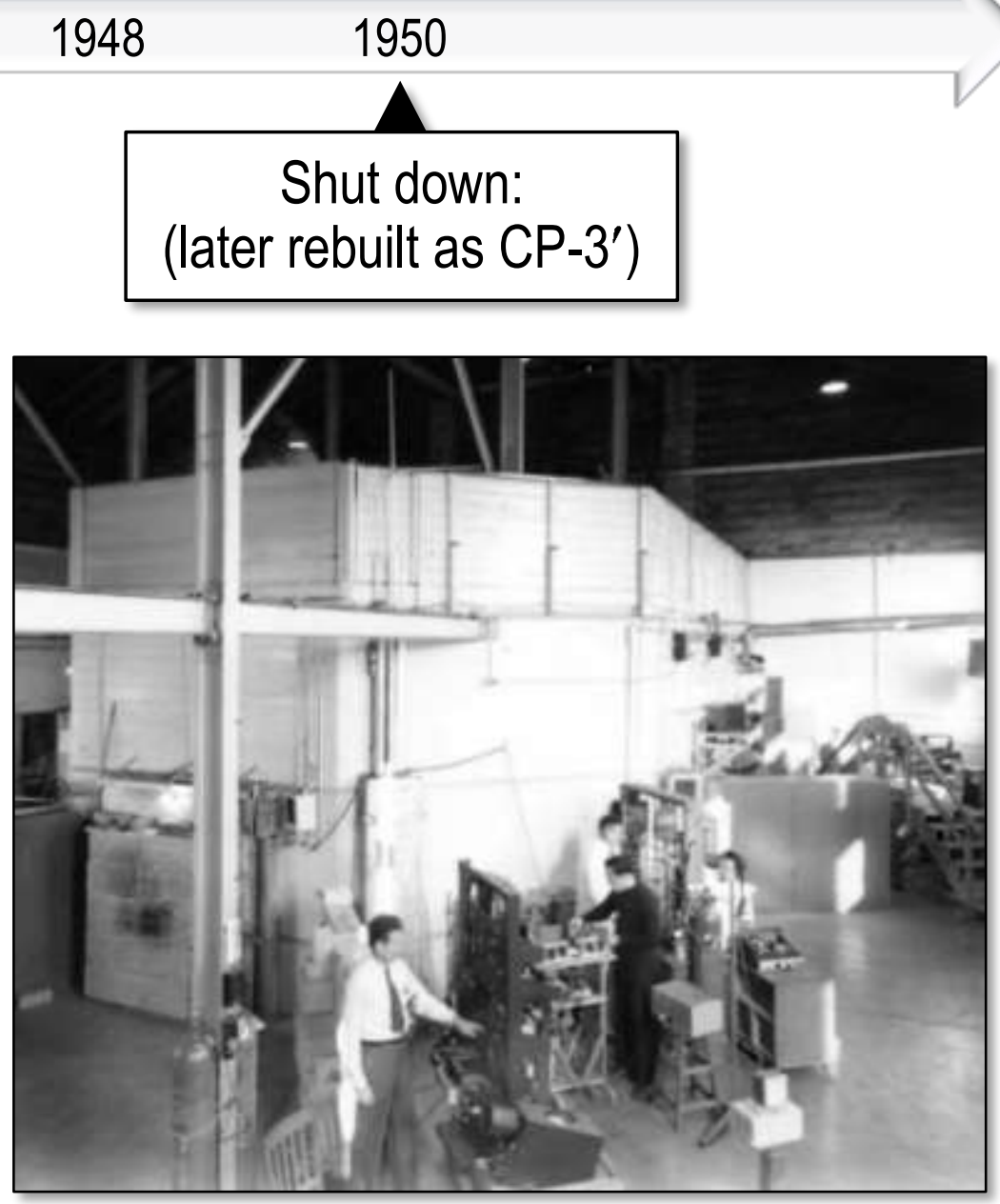

Courtesy Argonne National Laboratory 


\section{Early nuclear reactors: Neutron experimenters}

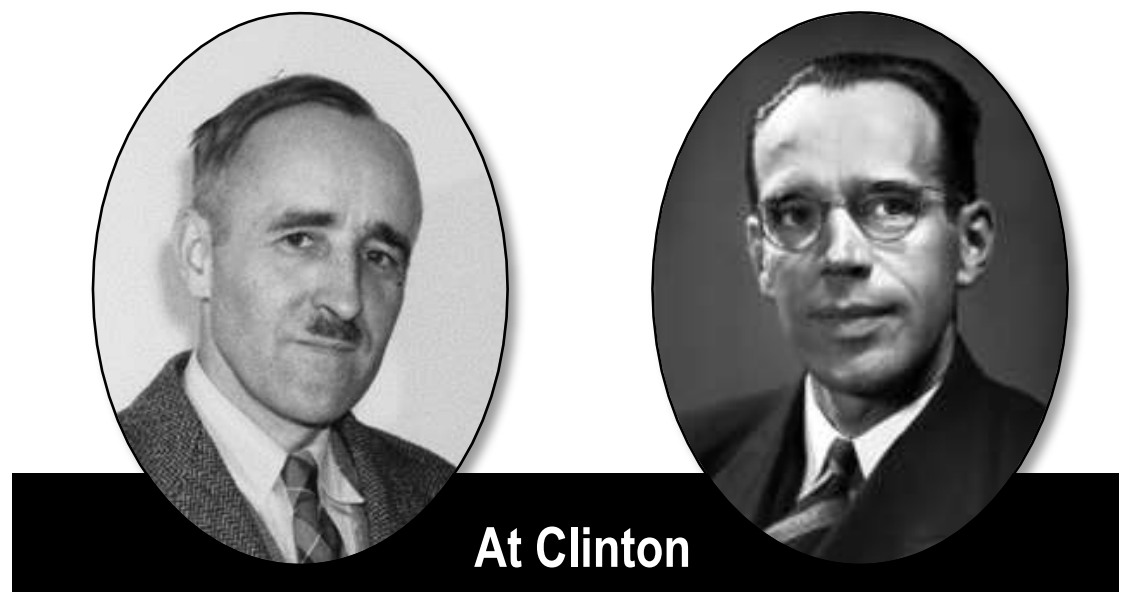

Ernest O. Wollan
Lyle B. Borst

(Courtesy Brookhaven National Lab)

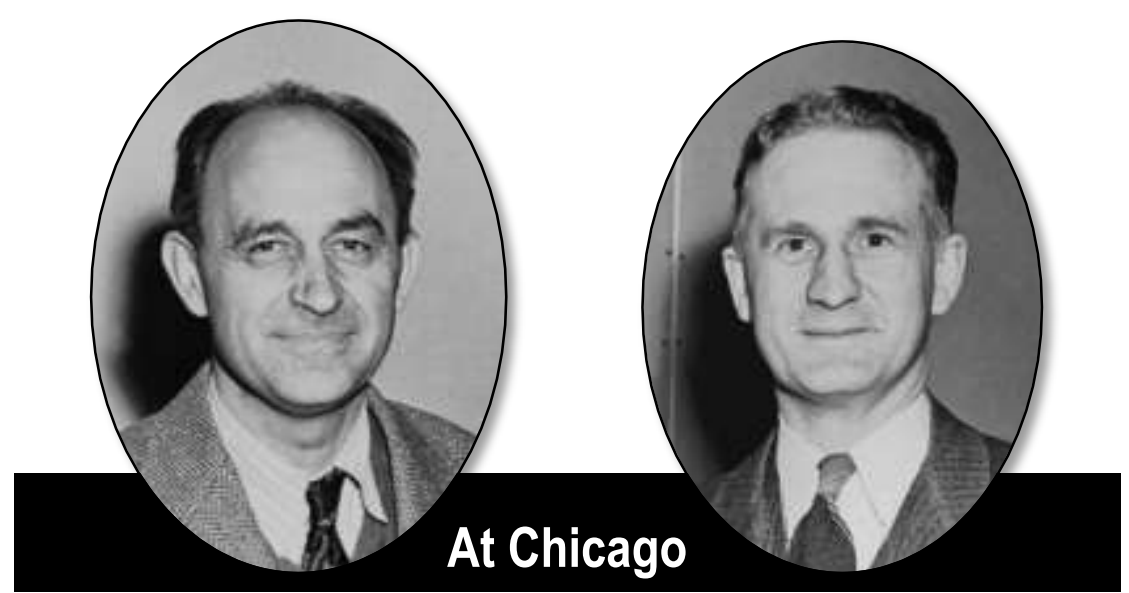

Enrico Fermi

(Courtesy Argonne National Lab)
Walter H. Zinn

(Courtesy Argonne National Lab) 


\section{May 1944: Wollan formally proposed to measure neutron diffraction at X-10}

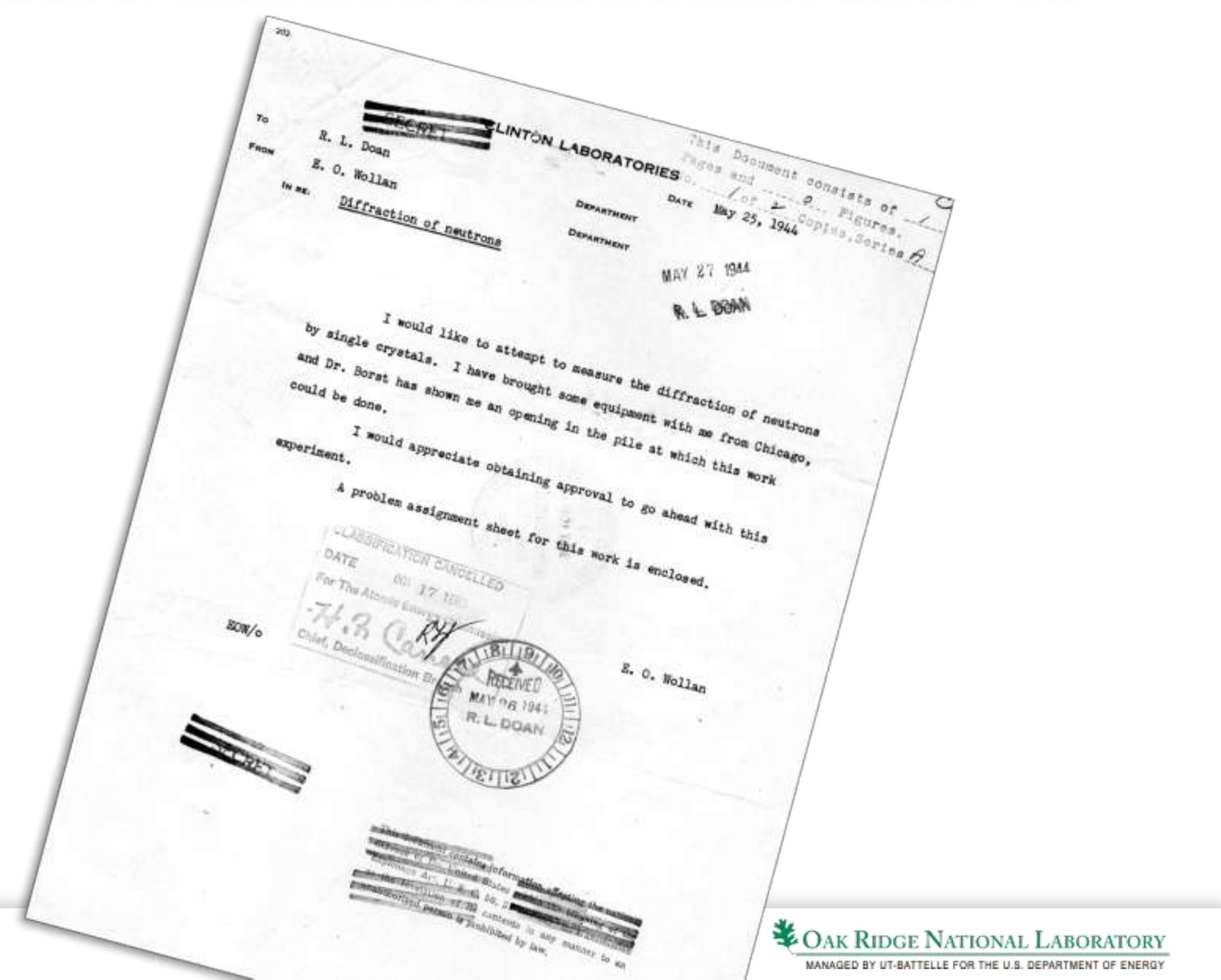




\title{
Experiments by Wollan and Borst in summer 1944 were unsuccessful
}

\begin{abstract}
May $31 \quad$ July 8 July 12
Neutron Crystal Spectromoter - B. O.llan, L. Borst

i neutron crystul snectronetor was brought down by E. 0 . .ollan. This was set up on the experimentul fuce of the pile usin: us a beam the neutrons energing fros: an open foll slot. The mpsun crystul used was $4 \times 6 \times 3 / 4^{\prime \prime}$ and apparently well-suited to the test. \& $\mathrm{BF}_{3}$ counter eot up ani uscd us a dotector sho of sutisfactory anounts of scattered rudiation. This rudiation varied : ith a.2le but showed no sharp Lune uaximu. The appurutus was renoved until i diagnosis of the difflizulty could be ade.
\end{abstract}

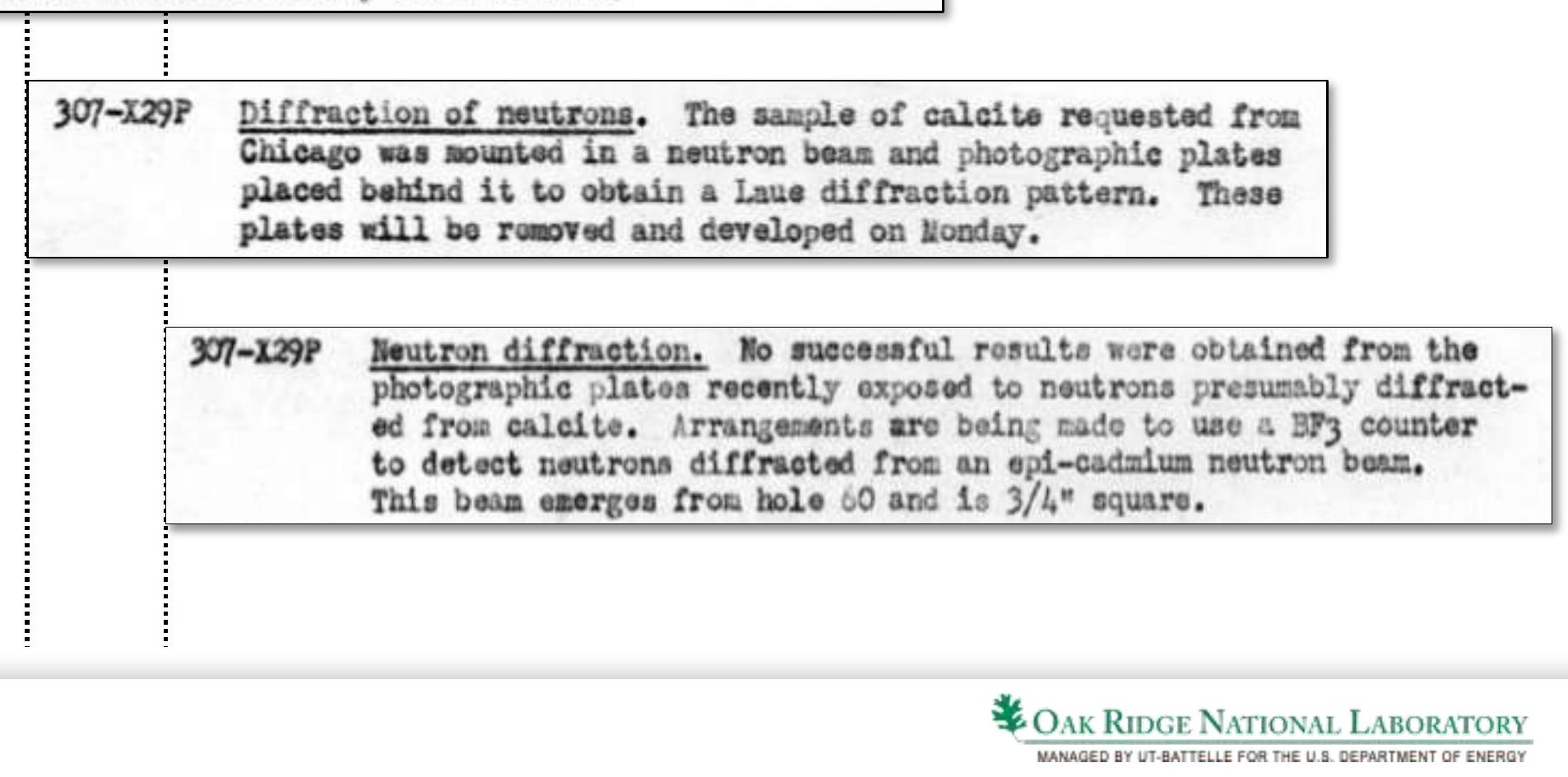




\section{July 1944: Fermi and Zinn initiated neutron diffraction experiments on CP-3}

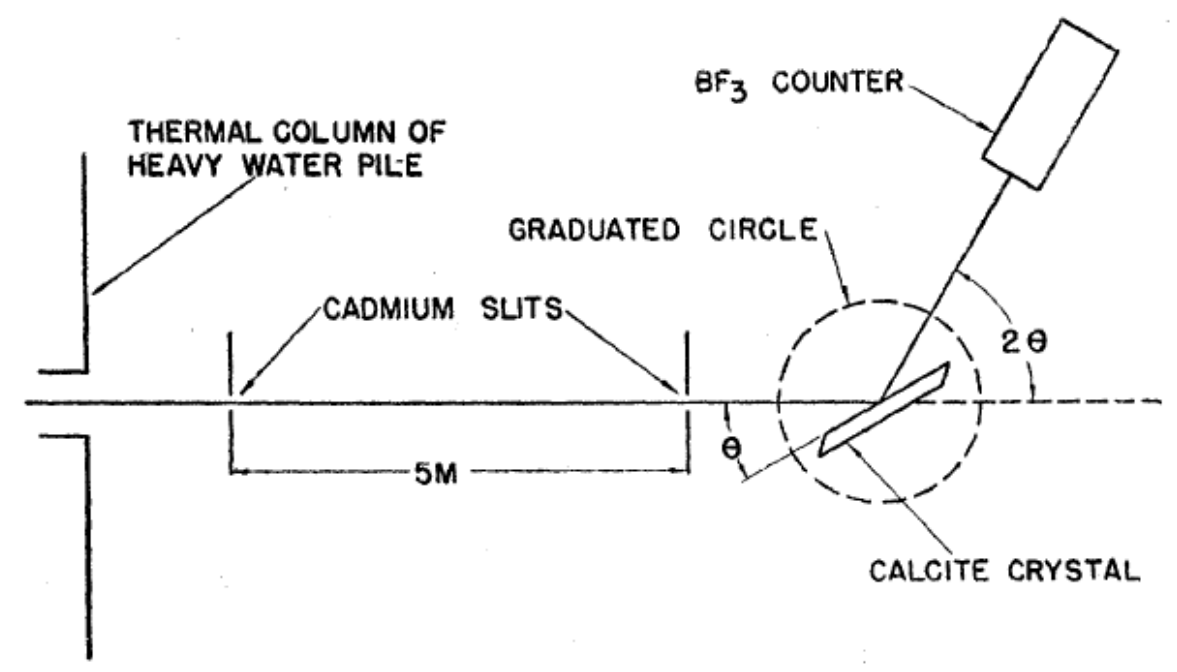

First experimental setup at CP-3

[W. H. Zinn, Phys. Rev. 71, 752-757 (1946)]
"The crystal, having the dimensions $6 \mathrm{~cm}$. x $12 \mathrm{~cm}$., was mounted on the table of a spectrometer with two divided circles. One circle measured the position of the crystal and the other the position of an arm which carried the $\mathrm{BF}_{3}$ counters.

The two circles could be geared together so that the counter always moved through twice the angle of the crystal. The distance from the crystal to the counter was $135 \mathrm{~cm}$." 


\section{August 1944: "Typical crystal rocking curve" reported by Zinn}

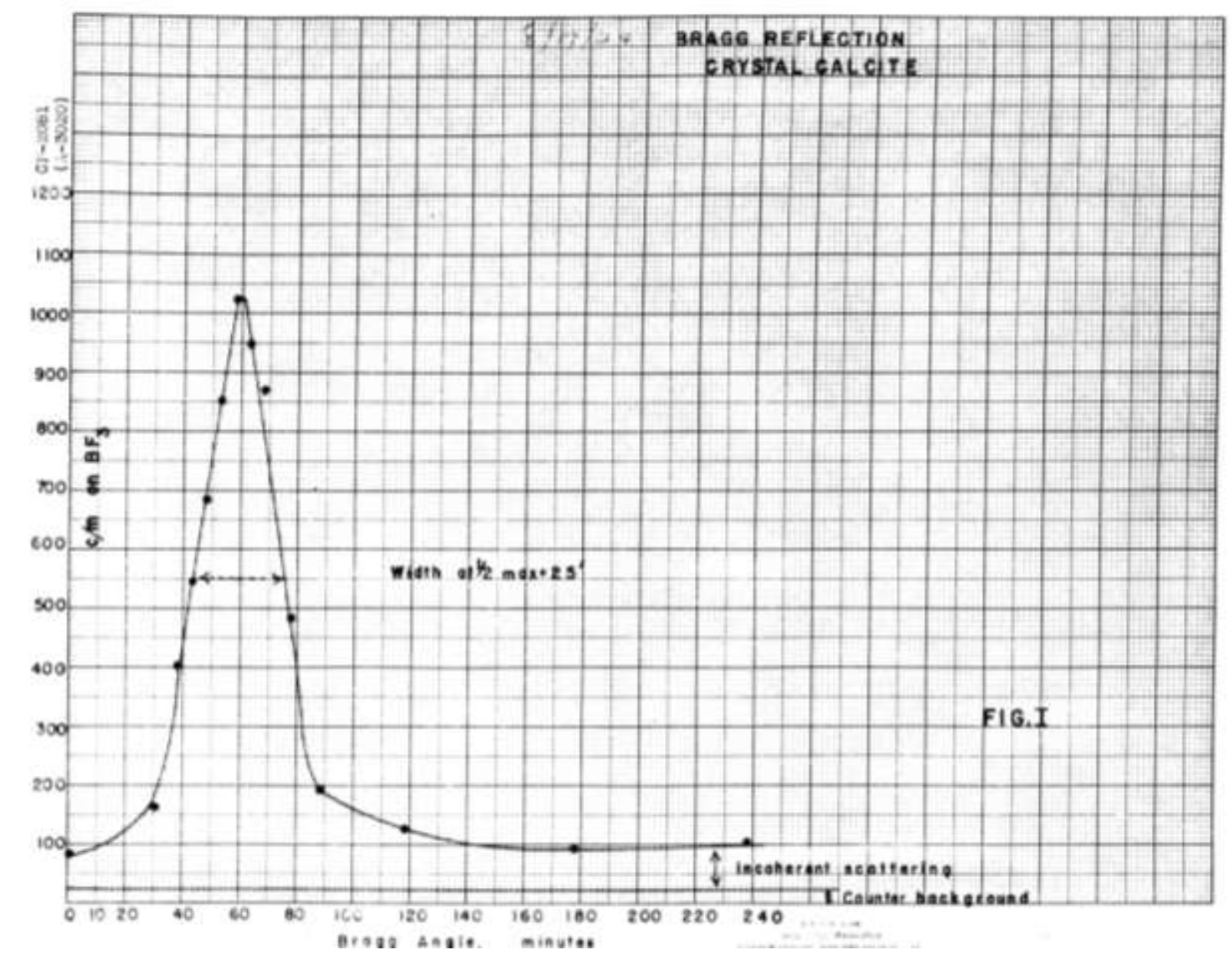

*ak Ridge National Laboratory 


\section{August 1944: Diffraction measurement reported by Zinn}

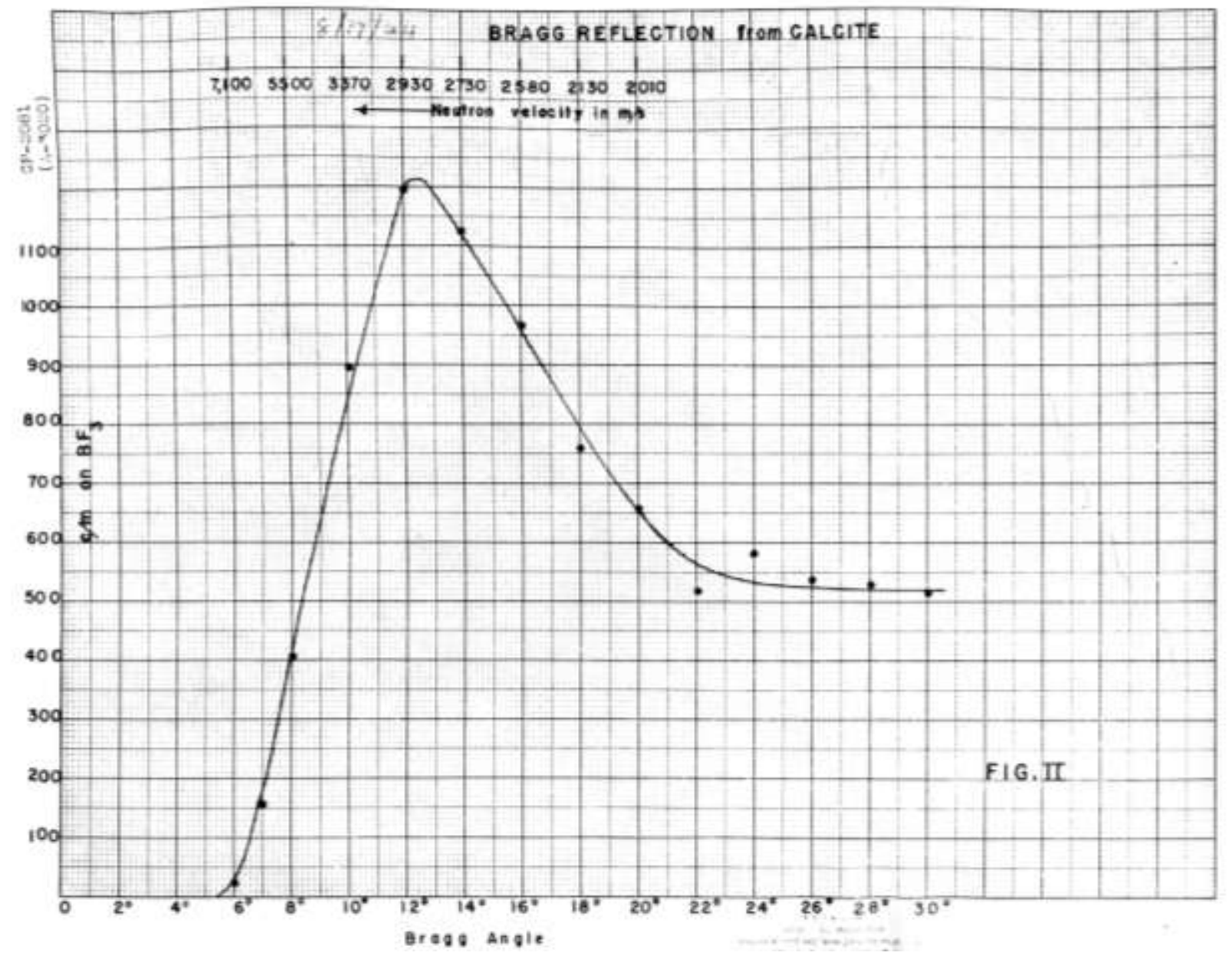




\section{Zinn continued his experiments with William Sturm}

"The Bragg reflection of thermal neutrons from a crystal has been further investigated from the viewpoint of determining its usefulness as a neutron spectrometer. It has been felt that the intensity available was sufficient to permit examinations of samples of rather small cross-sectional area."

- Metallurgical Project progress report, November 25, 1944

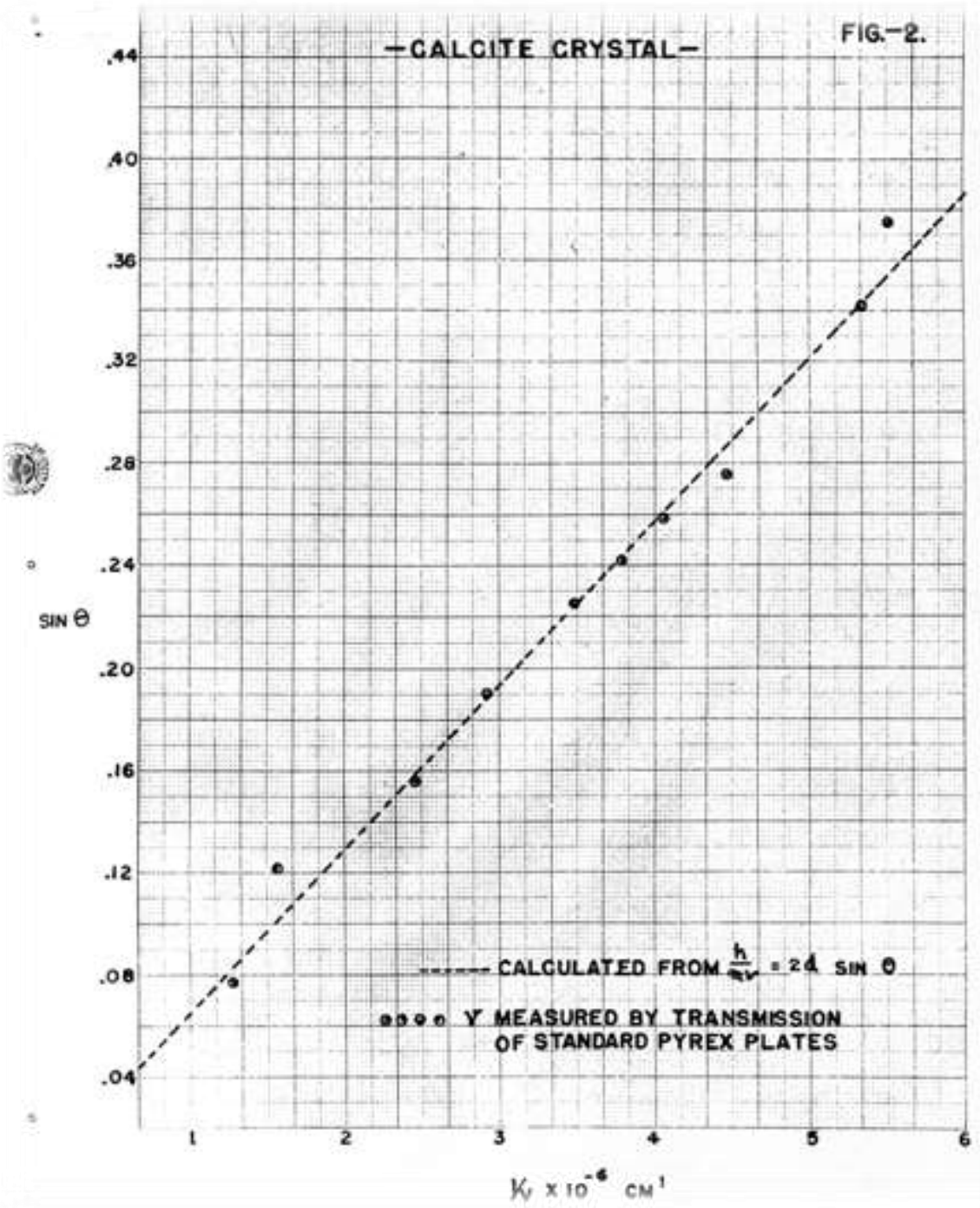




\section{Theoretical investigations of neutron diffraction were initiated at Chicago}

- 1944: Classified reports acknowledged experiments only by Zinn at Argonne and Borst at Clinton

- Goldberger and Seitz, The Diffraction of Neutrons by Crystals I, CP-2419, November 25, 1944 (declassified February 1, 1954)

- Seitz and Goldberger, The Diffraction of Neutrons by Crystals II, MDDC-1036, December 20, 1944 (declassified June 26, 1947)

- 1947: Attribution expanded to include Fermi at Argonne and Wollan at Clinton

Theory of the Refraction and the Diffraction of Neutrons by Crystals M. L. Goldrergirk, Institute for Nuclear Studies, University of Chicago, Chicago, Illinois AND

FreDERICK SEITz, Physics Departhent, Cartegie Institute of Technology, Pittsburgh, Pennsylianid (Received November 27, 1946)

The equations for the elastic scattering of treutrons by a single crystal, governing simple refraction, reflection, and Latue-Bragg scattering, are derived under the assumption that the scattering and absorption cross sections are ind
results is given in the final section of the paper.

1. INTRODUCTION

THE experiments on the scattering of neutrons by single crystals carried out at the Argonne Laboratories by Fermi and Zinnt and at
the Clinton Laboratories by Jorst and Wollan have given conclusive evidence that an appreciable part of the scattered intersity is coherent. In fact, a substantial part of the scattering takes place in accordance with the Laue-Bragg equations. The purpose of the present paper is to investigate the theoretical background for the scattering sorncwhat more fully than has been done previously and to summarize the results in a form that may be of use in the course of the development of the experinental work.

The scattering of slow neutrons by crystals has been of considerable interest since the earliest devclopment ${ }^{2}$ of a simplifect or semi-cmpiricial method of treating the interaction between neutron and nucjeus, Wick ${ }^{3}$ showed that one should expect highlly crystalline media to seatt flow neutrons in a way that is vary diferenty rom that expected for gases or completely

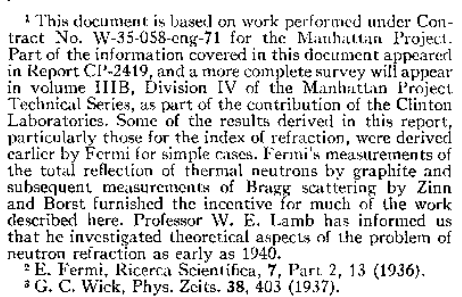
294 amorphous materiais because of the interference efects which occur. Wick's work has formecl the

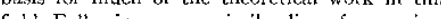
the

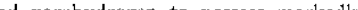
ide the car bection for used in the Buit Wipner formalim of resonance the subsequent experinental ver-

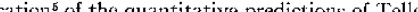
and Sctuwinger' on the basis of 'Teller's origin surcestion demonstrated that one can oxpect to obtairi a reusonable description of the scattering of slow ncutrons by polyatonic systems with the use of wave mecharics and the Breit Whignor

In the period following Wick's work, numerous investigators extended his treatment of the scattering of neutrons by crystals. Most prominent among these are the work of Pomerantschuk, Van Vleck Halpern, I-Tamermesh and Johrison, Seeger and Feler," and Weinstock." Pomerantschuk examined more carctully than Wick the flucnec of low temperatures upen the scattering 'J. Schwinger and E. Teller, Phys. Rev. 51,775 (1937) ${ }_{5}^{5}$. Halpern, L. Estermann, and O. Sern, Plyss. Rev.
$142(1937) ;$ L. W. Alvarez and K. S. I'itzer, Phyys. Rev (3) J. H. Van Vleck, Phys. Rev. 55, 924 (1939). Johnson,
O. Halpern, M. Hamcrmesh, and M. H. Johnon R. J. Sceger and E. Teiler, Phys. Rev. 62,37 (1942),
10 R. Weinstock, Yhys, Rev. 65, I (1944). 


\section{December 1944: Wollan reported success at Clinton}

\section{Upgraded equipment}

- Diffraction of neutrons from gypsum and rock salt achieved using "much more satisfactory" equipment:

- X-ray spectrometer borrowed from University of Chicago Physics Department

- $30 \mathrm{~cm}$ long, $5 \mathrm{~cm}$ diam $\mathrm{BF}_{3}$ proportional counter filled to $\sim 20 \mathrm{~cm} \mathrm{Hg}$ pressure and used end on to the diffracted beam

- Cadmium Soller slit placed in front of counter
Other improvements

- Shielding and "geometrical disposition" of the counter

- Thinner crystal slab
Source of neutrons

- Beam 1/4 in. wide by $3 / 4$ in. high

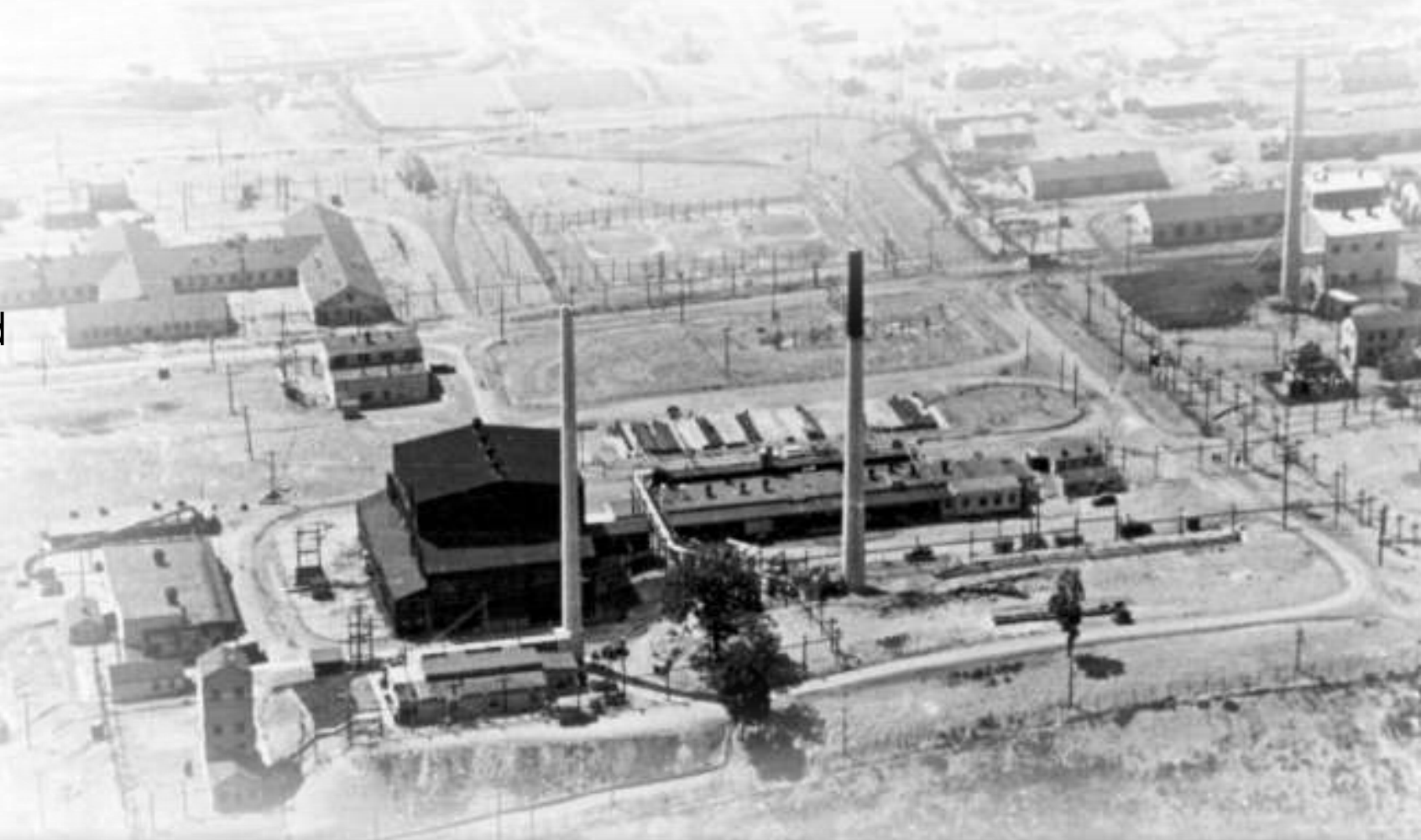




\section{Rock salt offered advantages for work "at energies up to $1 \mathrm{ev}$ or more"}

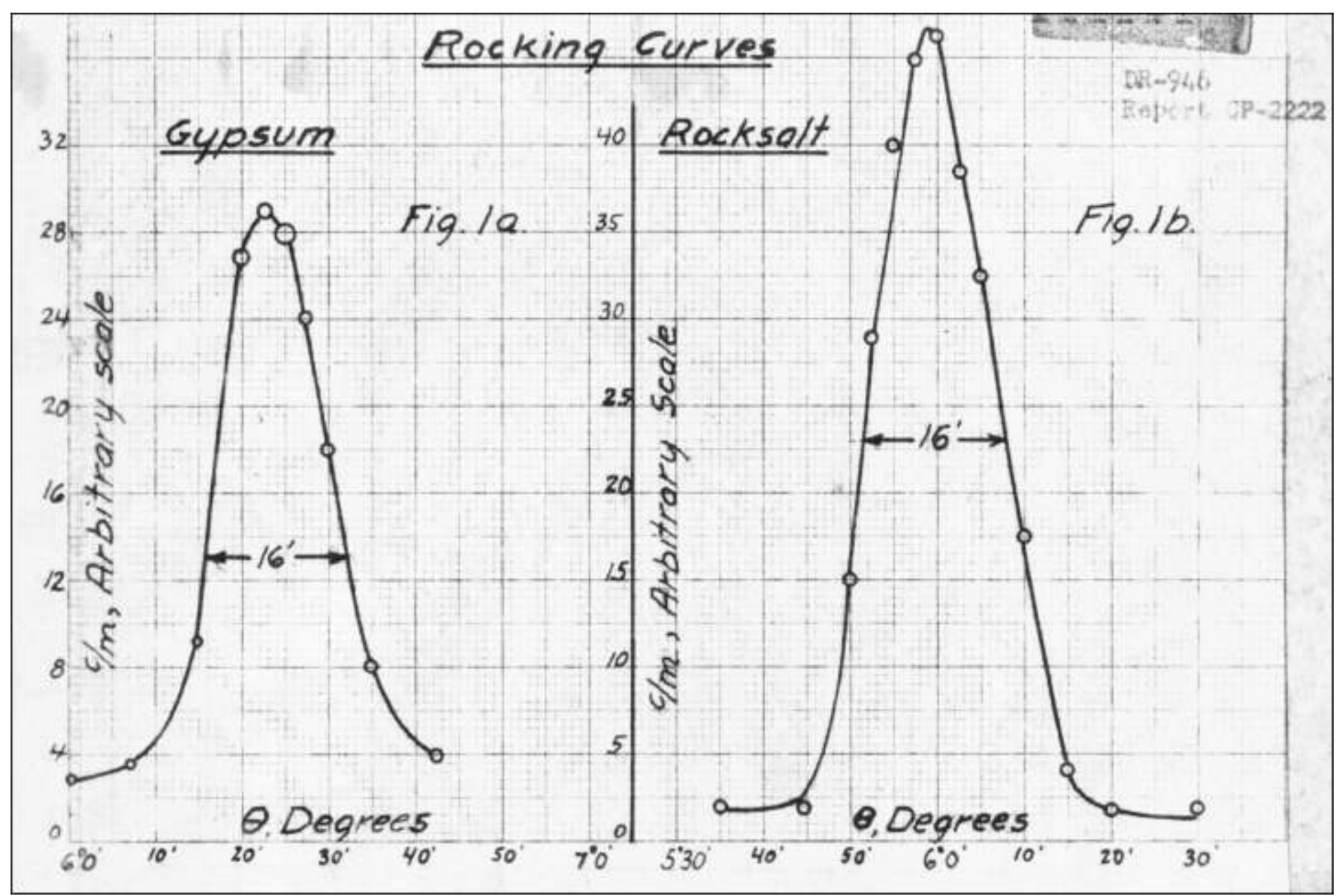




\section{January 1945: Wollan articulated the potential of neutron diffraction}

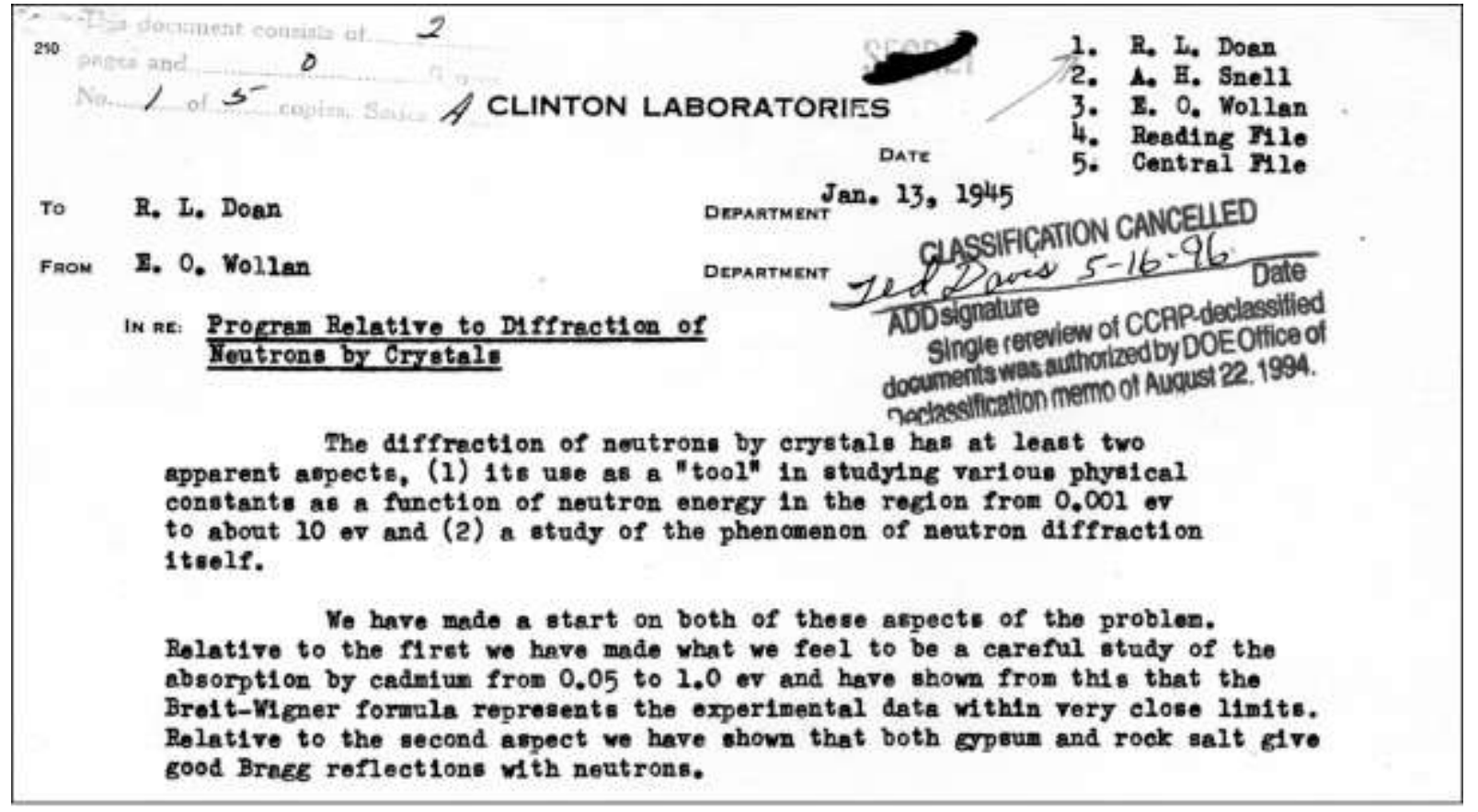

In general, I believe it can be said that neutron diffraction constitutes a very useful and simple physical "tool" when used in conjunction with a pile, and this will be especially so when piles of greater flux are available.
2. A study of the phenomenon of neutron diffraction as related

to the type of eryetal used 18 of interest although probably of lese 1mportance to the project. Ne have planned to divert a rather amall per cent of our time in this direction. We have ordered a rock salt cryetal which can be cut along a 111 plane so the coherent acatterlng by $\mathrm{Na}$ and $\mathrm{Cl}$ atoms can be independently determined. Th1s 18 of importance In chocking the diffraction theory al it relates to the role played by atoms of different spine and of different isotopic composition. Classification Cancelled *ergy

In general, I believe it can be sald that neutron diffraction constitutes a very useful and eimple physicel "tool" when used in conjunction wth a pile and this wil be especially so when piles of greater flux are avallable. 


\section{Wollan continued his explorations of neutron diffraction on the X-10 pile}

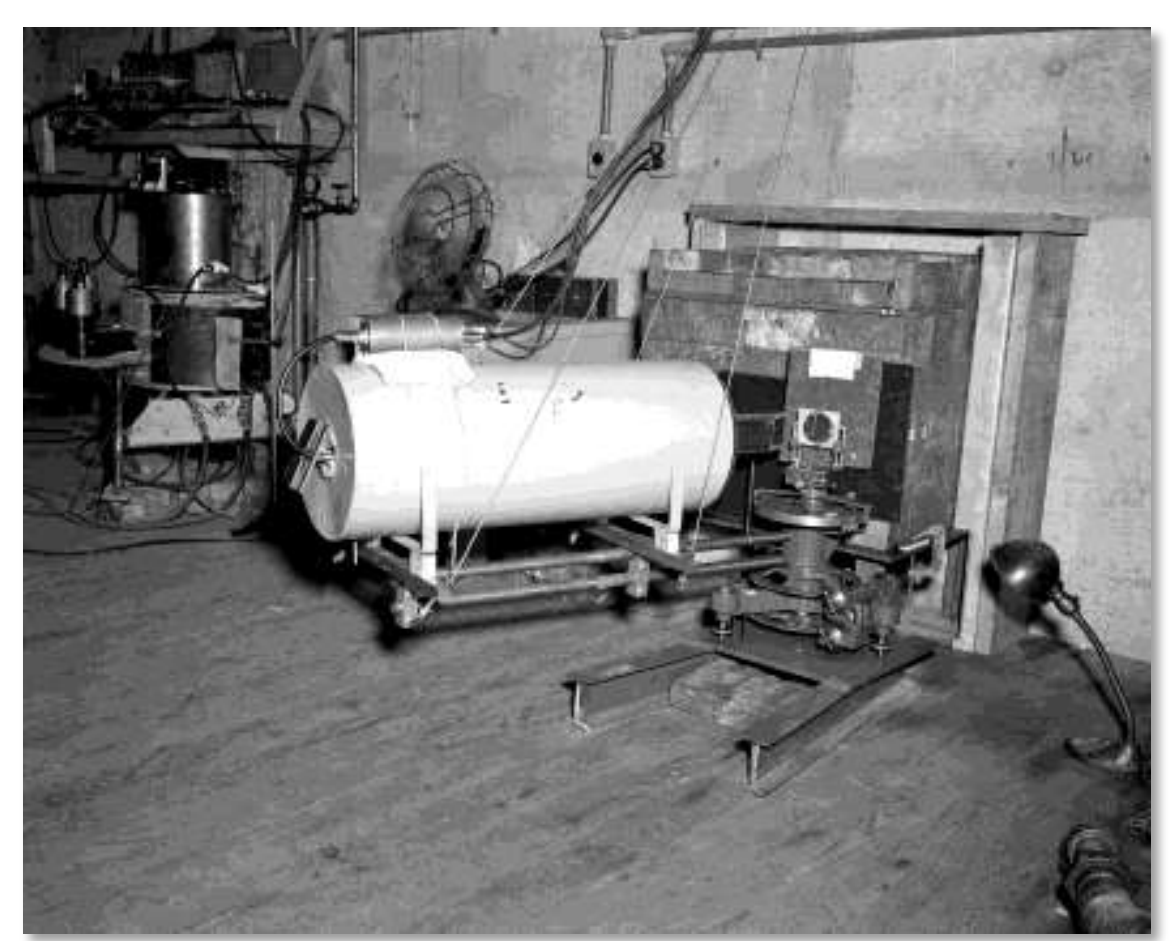

1946: Wollan's double-axis spectrometer, modified for use in powder diffraction studies

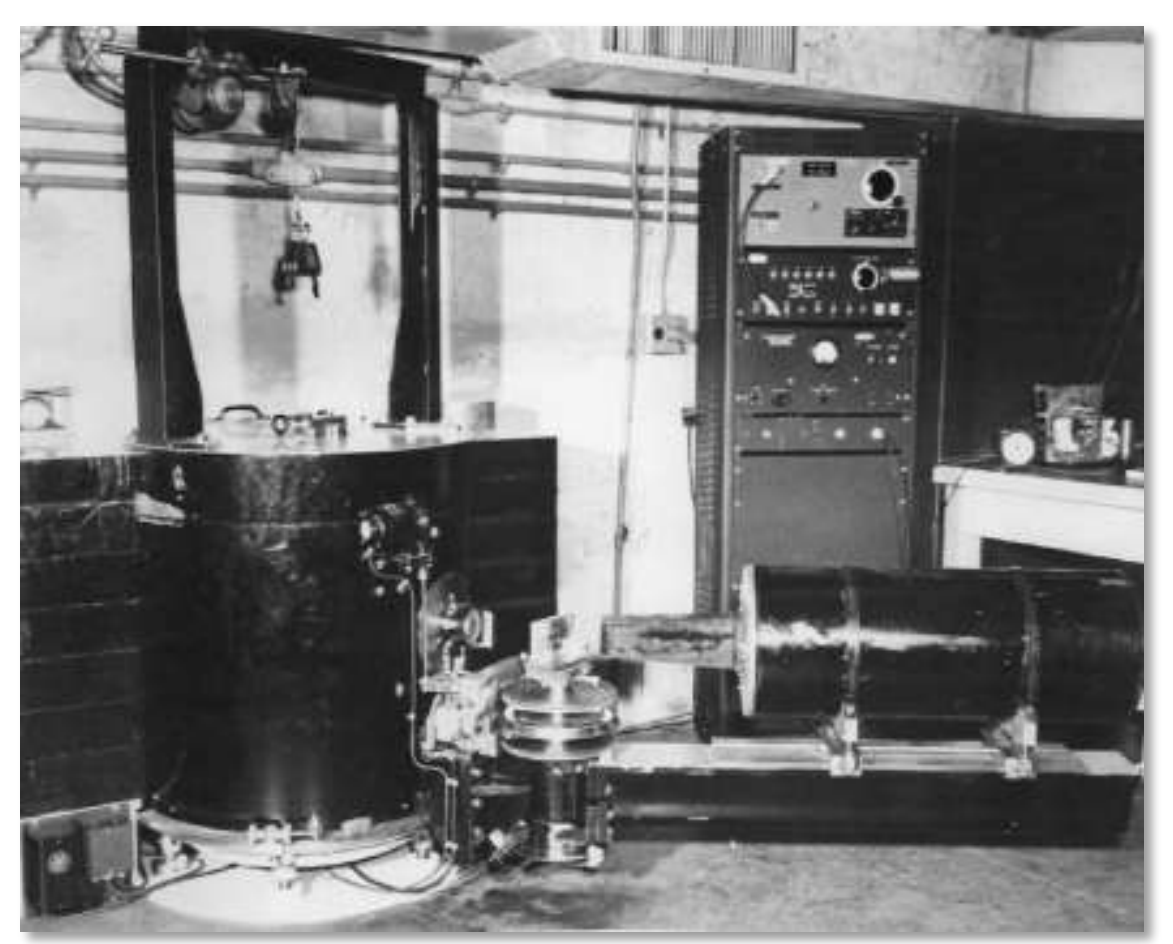

1949: Double-axis spectrometer constructed specifically for neutron use 


\section{Wollan and Shull pioneered the field of neutron diffraction}

- Development of techniques and instrumentation

- Application to previously insoluble problems in:

- Crystallography and chemical binding

- Nuclear studies

- Magnetism

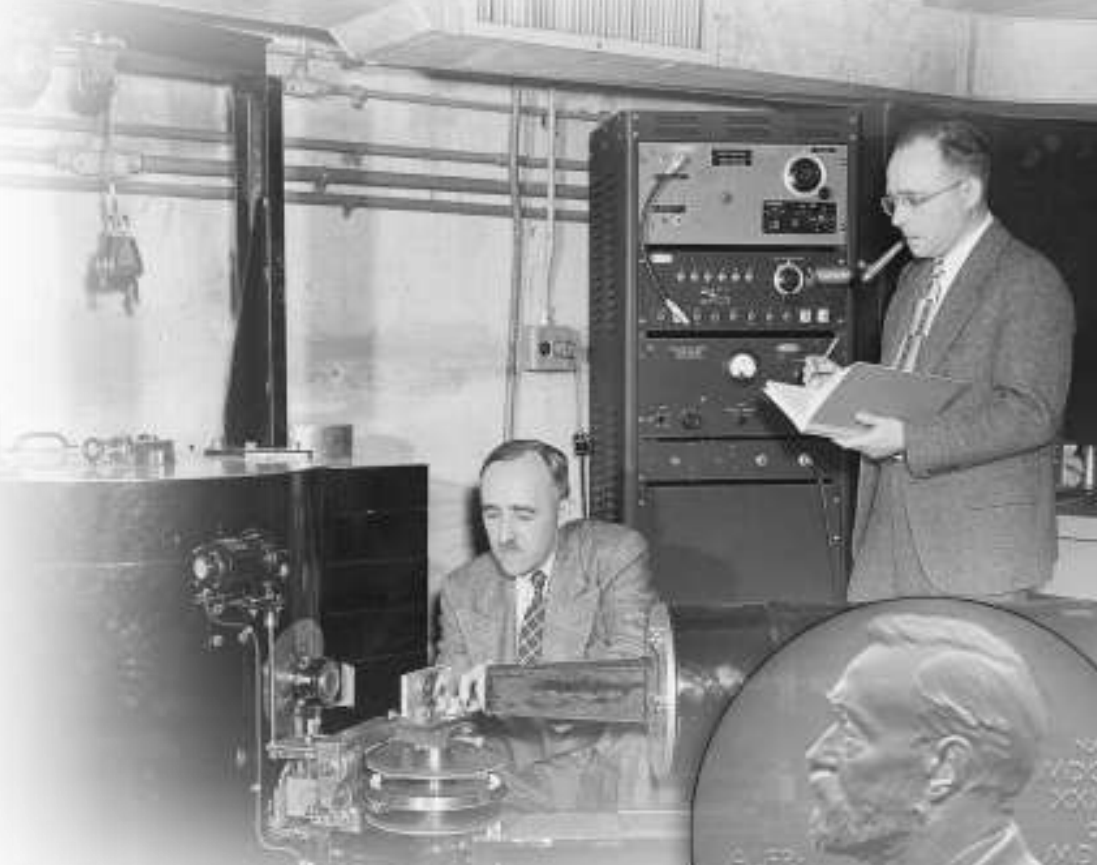

1994: Clifford Shull

received the Nobel Prize in Physics for the development of neutron scattering techniques to analyze condensed matter 


\section{Discussion}

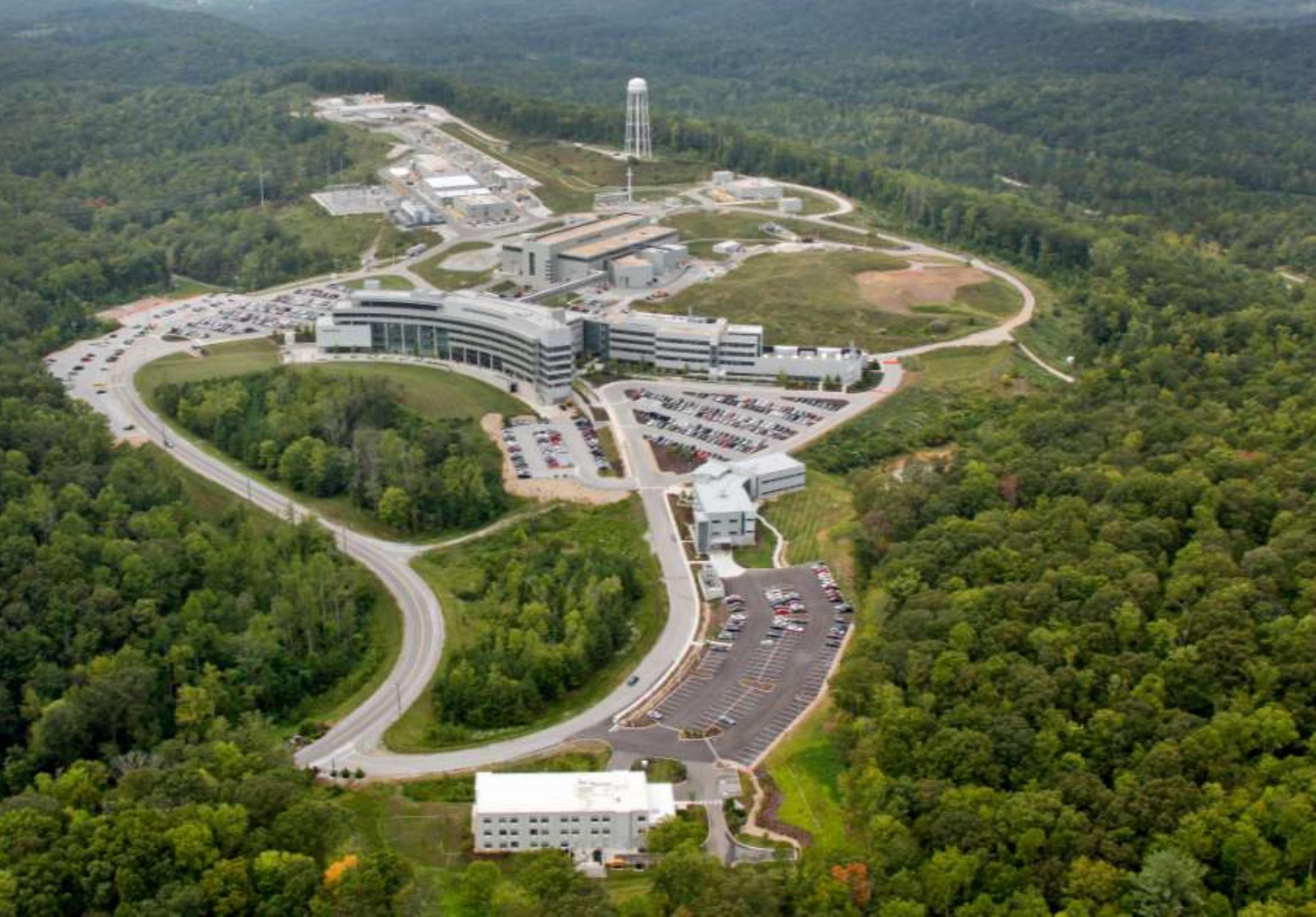

